\title{
Incidence of milling energy on dry-milling attributes of rice starch modified by
}

$$
\text { planetary ball milling }
$$

$$
\text { Luciana C. González }^{1,2} \text {; María A. Loubes }{ }^{1,2} \text {; Marcela P. Tolaba }{ }^{1,2^{*}}
$$

${ }^{1}$ University of Buenos Aires, Faculty of Exact and Natural Sciences. Industry Department. Buenos Aires, Argentina.

${ }^{2}$ CONICET - University of Buenos Aires. Institute of Food Technology and Chemical Processes (ITAPROQ). Buenos Aires, Argentina.

* Corresponding author: mtolaba@di.fcen.uba.ar. Intendente Güiraldes 2160, Departamento de Industrias, Ciudad Universitaria, C1428EGA.

\section{ABSTRACT}

Rice starch was modified in a planetary mill. The effects of milling energy (E) on physicochemical and functional properties were investigated. Particle size, crystallinity degree and gelatinization enthalpy were reduced with the increase of milling energy. The effect of $\mathrm{E}$ on particle size reduction could be predicted by generalized Holmes' model. Heat dissipation was evidenced during milling through the non-linear relationship between size reduction ratio and milling energy. Hydration and pasting properties were significantly affected. Water soluble index (WSI) and swelling power (SP) increased with increasing both energy and temperature of hydration test. For the greatest energy and temperature level $\left(85^{\circ} \mathrm{C}\right)$, WSI value varied between $1.5-29.7 \%$ and $\mathrm{SP}$ value between $7.4-16.4 \mathrm{~g} / \mathrm{g}$, relative to native starch. The crystallinity showed negative relationships with WSI and a SP. Regards to pasting properties, peak viscosity (PV) decreased from $4384 \mathrm{mPa}$.s to 544 
$\mathrm{mPa} . \mathrm{s}$ as E varied between $0 \mathrm{~kJ} / \mathrm{g}$ and $4.08 \mathrm{~kJ} / \mathrm{g}$. Peak, setback and final viscosities parameters showed a linear relationship with the particle size. There were found strong correlations between physicochemical and functional properties of modified starches, which evidenced the dependence of the modification on milling severity. Planetary ball milling is presented as an eco-friendly alternative to modify native rice starch properties.

Keywords: grinding energy, crystallinity, particle size, high impact mill, functional properties.

\section{INTRODUCTION}

Starch is one of the most abundant carbohydrates in plants. Particularly, rice starch constitutes $90 \%(\mathrm{w} / \mathrm{w})$ of milled rice and it has the characteristic of being gluten-free and thus, suitable for the elaboration of products intended for celiac people. Starches are widely used as food ingredients to improve appearance, texture, and overall acceptability of foodstuffs and they are characterized by their great versatility for applications in the food and beverage industry. The use of starches allows the simplification of labeling by substituting certain additives, reducing formulation costs and ensuring some texture attributes in the final product (Taggart, 2004). However, starches have some limitation for their application, due to the tendency to retrogradation and low solubility in water, which restrict their functional properties. For this reason, they are rarely consumed and industrially used in the native state, and there is a need to modify them to improve the positive attributes and to exclude the shortcomings of the native starches (Alcázar-Alay \& Meireles, 2015; Guerzoni, Gianotti, \& Vernocchi, 2011). 
The starch modification industry is in constant progress. Different methods have been developed: chemical, physical and enzymatic or combinations of them; to carry out changes in the starch functionality. However, there is an increasing tendency in the use of physical methods due to their simplicity, low cost and their contribution to food safety because of the absence of chemical or biological agents (Ashogbon \& Akintayo, 2014). High-pressure treatment, gamma irradiation, microwave use and high-impact milling (Błaszczak et al., 2007; Deka \& Sit, 2016; He et al., 2014; Zhu, 2016) are some examples of the current physical methods applied, with little or no waste production, as alternatives to modify the physicochemical properties of starches. Among high-impact milling methods, the planetary ball mill is presented as a novel technology recently applied to cereals and their derivatives by dry and wet milling at laboratory scale (He et al,, 2014; María A. Loubes \& Tolaba, 2014). At industrial scale, planetary ball mills for continuous operation (up to five tons of powder per hour) are available only for mineral grinding (Technics and Technology of Disintegration Co., 2015).

It has been found that grinding in planetary ball mill can achieve significant modifications in the morphology and crystalline structure of the starch granules, giving them changes in physicochemical properties, useful for various industrial applications. The degree of modification given by the planetary ball mill depends on both the intensity of the process and the nature of the starch, and is associated with the distortion of the ordered structure and the increase of the amorphous phase (Tan et al., 2015). Some researchers have shown that the alteration conferred by the planetary mill can reach not only strictly crystalline regions, but also double-helix structures located in less ordered areas (Liu, Ma, Yu, Shi, \& Xue, 2011). 
72 The structural modifications, changes in particle size distribution and starch damage,

73 resulting from the milling process, are reflected in changes in hydration and pasting 74 properties of starch suspensions (Barrera et al., 2013; Chiang \& Yeh, 2002; Hossen et al., 75 2011; Zhang, Zhao, \& Xiong, 2010).

Literature reports show a constant interest to investigate starch behavior during food processing as well as to evaluate the aptitude of starch as functional ingredient in different food products (Wani et al., 2012). However, there are currently no publications on starch grinding in high-impact mills, where the energy used for the process is exposed. Instead, the milling time and the rotation speed are often reported which are strongly dependent on the type and capacity of the selected mill. The use of specific milling energy would facilitate the process simulation by using energy-particle size milling models (Rhodes, 2008). Size reduction by milling is an operation with high energy consumption and low efficiency. A measure of the efficiency of the operation is based on the energy required to create a new surface (McCabe, Smith, \& Harriot, 2007). With the postulates of Rittinger's, Kick's and Bond's laws, it is possible to predict the needed energy to generate a determined particle size reduction. Moreover, there have been attempts to generate a single equation to predict the performance of various materials during milling, such as Holmes' and Hukki's models (Rhodes, 2008).

Therefore, the aim of the present work was to study the potential of the planetary ball mill to obtain physically modified rice starch and to produce improvements in its physicochemical properties, as a function of the grinding energy. The aptitude of the general milling equation to describe the energy-size relationship was also evaluated. The modifications achieved in the crystalline structure and particle size distribution of the starch, and their impact on the hydration and pasting properties were investigated. 


\section{MATERIALS AND METHODS}

98

99

100

101

102

103

104

105

106

107

108

\subsection{Materials}

Native rice starch of food grade (Remy B7, Beneo GmbH, Germany) was supplied by Saporiti S.A. (Buenos Aires, Argentina). The amylose content of the rice starch was 18.4 $\mathrm{g} / 100 \mathrm{~g}$ of total starch, determined according to an iodine binding-based method of $\mathrm{Li}$, Wang, and Zhu (2016). Chemical composition (dry basis) of rice starch was provided by the manufacturer as follows: $88.7 \%$ carbohydrates (by difference), $13.7 \%$ moisture, $1.0 \%$ protein, $0.0 \%$ lipid, $0.2 \%$ ash.

\subsection{Dry milling treatment}

The pulverization of rice starch was performed in a planetary ball mill model PM 100 manufactured by Retsch (Retsch $\mathrm{GmbH}$, Germany) with zirconium jar (500 mL) and balls (diameter: $5 \mathrm{~mm}$ ) at different levels of milling energy within $0.26-4.08 \mathrm{~kJ} / \mathrm{g}$ and constant rotational speed of $400 \mathrm{rpm}$. Milling energy represents the energy provided to the content of the milling jar (sample and balls); therefore, a previous calibration was required using an empty jar (energy at "ralenti"). The milling protocol involved pauses of $40 \mathrm{~min}$ each $10 \mathrm{~min}$ of grinding, by this procedure the overheating of the starch was avoided, and the sample temperature never exceeded $55^{\circ} \mathrm{C}$ (values of sample temperature are reported in Table 1). A change in the rotational direction of the jar was established every 30 seconds. Starch sample (115 g) and five times weight balls were placed into the grinding jar up to about two thirds of its capacity according to method reported by Loubes (2015). Native rice starch 
was adopted as control sample. Moisture content was determined by triplicate after milling treatment, according to (AOAC, 2000). It decreased as the milling energy increased from $12.8 \%$ (d.b.) to $10.8 \%$ (d.b.), for $0.26 \mathrm{~kJ} / \mathrm{g}$ and $4.08 \mathrm{~kJ} / \mathrm{g}$, respectively.

\subsection{Particle size distribution}

Particle size distribution was determined by static light scattering (SLS) in a Mastersizer 2000 device (Malvern Instruments Ltd., Worcestershire, UK), equipped with a dispersion unit Hydro 2000MU. The pump was operated at $1800 \mathrm{rpm}$. Bi-distilled water was used as dispersing agent for which diffraction index and absorptivity were 1.53 and 0.001 respectively. The instrument provides size distribution parameters in terms of volumetric fraction: $\mathrm{D}_{10}, \mathrm{D}_{50}$ (median) and $\mathrm{D}_{90}$ (corresponding to the diameters of $10 \%, 50 \%$ and $90 \%$ of cumulative frequency respectively). From the equipment's software (Malvern Application v5.60, Malvern Instruments Ltd., Worcestershire, UK) the specific surface area (SSA), the mean volumetric diameter (D4.3) and the "Span" index (Eqn. 1), as a measure of size dispersion, were obtained. The particle sizes are reported as the average of five readings made on a sample.

$$
\text { Span }=\left(\mathrm{D}_{90}-\mathrm{D}_{10}\right) / \mathrm{D}_{50} \quad(\text { Eq. } 1)
$$

\subsection{Energy - size milling models}

The generalized model proposed by Holmes (1957) was used to simulate the relationship between the specific milling energy $(\mathrm{E})$ and the particle size (x), for which the postulates of 
141 Rittinger's, Kick's and Bond's laws are presented as special cases and assume the value of

$142 n$ as 2,1 and 1.5 , respectively:

143

144

145

146

147

148

149

150

151

152

153

154

155

156

157

158

159

160

161

162

163
$\mathrm{dE} / \mathrm{dx}=-c\left(1 / \mathrm{x}^{n}\right)$

(Eq. 2)

Such equation suggests that the energy required to produce a small change in the size of unit mass can be expressed as a power function of the size of the material (BarbosaCánovas, Ortega-Rivas, Juliano, \& Yan, 2005).

If $\mathrm{D}_{50}$ is adopted as a measure of $\mathrm{x}$ the integrated form of the equation yields:

$$
\int_{0}^{\mathrm{E}} \mathrm{dE}=-\mathrm{C} \int_{\mathrm{D} 50 \mathrm{i}}^{\mathrm{D} 50 \mathrm{f}}\left(1 / \mathrm{D}_{50}{ }^{\mathrm{n}}\right)
$$

$$
\mathrm{E}=(c /(1-n))\left(\mathrm{D}_{50 \mathrm{i}}{ }^{1-n}-\mathrm{D}_{50 \mathrm{f}}^{1-n}\right)
$$

Where $\mathrm{E}$ is the specific energy required to pulverize the particle from $\mathrm{D}_{50 \mathrm{i}}$ (initial diameter: median of native starch) to $\mathrm{D}_{50 \mathrm{f}}$ (final diameter: median of modified starch). The parameters of the model: $n$ and $c$ can be obtained by regression analysis from experimental data $(\mathrm{E}$ "versus" $\left.\mathrm{D}_{50 \mathrm{f}}\right)$. For $n$ equal to 2 the generalized equation becomes to Rittinger model which has been successfully applied to model ultra-fine grinding (Rhodes, 2008).

Linear and non-linear relationships between the specific milling energy and the size reduction ratio $\left(\mathrm{R}_{\mathrm{r}}=\mathrm{D}_{50 \mathrm{i}} / \mathrm{D}_{50 \mathrm{f}}\right)$ have been also used to follow the milling operation (Barbosa-Cánovas et al., 2005; Rhodes, 2008). 
Regression analyses were performed using the Statgraphics Centurion (version XVI, Statistical graphics Corporation, Inc., Virginia, USA) statistical software.

\subsection{X-ray diffraction}

X-ray diffraction analysis were performed using a Philips diffractometer model X'Pert MPD (PANalytical B.V., Netherlands) under K $\alpha$-radiation of copper $(\lambda=0.154 \mathrm{~nm})$. The scanning region of the diffraction angle (20) was $6-32^{\circ}$ and the scanning speed was set at $0.9 \% \mathrm{~min}$. The iterative method developed by Roa, Santagapita, Buera, and Tolaba (2014) was adopted in order to set a baseline for the scattering and to calculate the total and amorphous areas which were quantified using OriginPro Software version 8.0 (OringinLab Corporation, Northampton, EE. UU.). The crystallinity degree (CD) was calculated as the ratio between the crystalline and the amorphous areas, obtained from the diffraction patterns, according to:

Where TA, AA are the total and amorphous areas, respectively, and (TA-AA) represents the area corresponding to crystalline peaks. Mean and standard deviation values of duplicates are reported.

\subsection{Thermal properties}

Thermal properties were determined by differential scanning calorimetry (DSC), in a Mettler-Toledo DSC calorimeter, model 822 (Schwerzenbach, Switzerland). 
187 For the analysis, $6 \mathrm{mg}$ of each sample was weighed exactly in Mettler pan of $160 \mu \mathrm{l}$

188 capacity and bi-distilled water was added in a starch:water ratio of 1:3 (m/v). Subsequently,

189 the pan was sealed and equilibrated for 24 hours at room temperature before performing the

190 calorimetric test, which was carried out with a heating cycle comprised between $25^{\circ} \mathrm{C}$ and

$191100^{\circ} \mathrm{C}$, with a constant heating rate of $10^{\circ} \mathrm{C} /$ minute, taking an empty pan as reference.

192 The resulting thermograms were analyzed with the STARe Software software version 6.1

193 (Mettler Thermal Analysis) to obtain the peak temperature (Tp) and the enthalpy of 194 gelatinization $(\Delta \mathrm{H})$, which was calculated from the integration of the endothermic 195 transition curve. The thermal parameters were recorded in triplicate.

196

197
(Eq. 5)

(Eq. 6) 
211

212

213

214

Pasting properties of starch samples were determined using a Rapid Visco Analyser RVA 4500 (Perten Instruments, Australia). Starch (3.5 g) was dispersed in $25 \mathrm{~g}$ of distilled water contained in an aluminum pan which was subjected to a controlled heating-cooling cycle. Thermal cycle involved an initial thermal equilibration at $50^{\circ} \mathrm{C}(1 \mathrm{~min})$ followed by dynamic heating at $12.5^{\circ} \mathrm{C} / \mathrm{min}$, while stirring at $160 \mathrm{rpm}$, up to $95^{\circ} \mathrm{C}$. Then the sample was held at $95^{\circ} \mathrm{C}(2.5 \mathrm{~min})$ and finally it was cooled to $50^{\circ} \mathrm{C}$ at $12^{\circ} \mathrm{C} / \mathrm{min}$ and maintained at $50^{\circ} \mathrm{C}$ ( $\left.2 \mathrm{~min}\right)$. The following parameters were obtained from the pasting curve, using the software Thermocline, Versión 3.15 (Perten Instruments, Macquarie Park, Australia): initial pasting temperature $(\mathrm{PT})$, peak viscosity $(\mathrm{PV})$, peak time $(\mathrm{Pt})$, breakdown $(\mathrm{BD})$, trough viscosity (TV), setback (SB) and final or cool paste viscosity (FV). Measurements were performed in duplicate.

\subsection{Statistical analysis}

Analysis of variance (ANOVA), regression and correlation analyses (correlation coefficients from the matrix of Pearson) were performed using the statistical program Statgraphics Centurion version XVI (Statistical graphics Corporation, USA), comparing the means by the least significant difference test of Fisher (LSD), with a confidence level of 95 or $99 \%$.

\section{RESULTS AND DISCUSSION}

\subsection{Milling energy}


In the present work the mill was operated at a constant rotational speed of $400 \mathrm{rpm}$ and the energy involved in the grinding of rice starch in the planetary ball mill was linearly increased with the grinding time $\left(\mathrm{R}^{2}=0.9996\right)$ as it can be appreciated in Table 1 . Due to Coriolis effect, a significant reduction of processing time can be achieved by using the planetary ball mill in comparison with traditional ball milling (Retsch, 2009).

\subsection{Particle size}

Particle size distribution of control was bimodal with the volumetric fraction of the peak at $148.3 \mu \mathrm{m}$ higher than that of peak at $28.2 \mu \mathrm{m}$. In contrast, monomodal size distributions were observed for grinded starches. Peaks at 10.7 and $12.3 \mu \mathrm{m}$ were found by using 0.26 and $0.52 \mathrm{~kJ} / \mathrm{g}$ respectively. Such peaks presented a shoulder on the right denoting a residual fraction of starch particles with a larger size. However, with a further increase of milling energy the shoulder disappears. A symmetric and well defined peak at $12 \mu \mathrm{m}$ was observed using $1.04 \mathrm{~kJ} / \mathrm{g}$ or higher milling energies. Particle size converged to this asymptotic peak value as milling energy increases within the experimental range.

Characteristic parameters: median $\left(\mathrm{D}_{50}\right)$, specific surface area (SSA) and "Span" index which were obtained from particle size distribution are showed in Table 1, as function of milling energy. $D_{50}$ values of modified rice starches were significantly lower than that of control due to the drastic reduction of particle size as a consequence of high impact milling. The significant reduction of "Span" index (up to $49 \%$ compared to the control) with increasing milling energy evidenced the potential of planetary ball mill to produce a very homogeneous granulometry. The specific surface area of the modified starches was higher than that of control. The highest value of SSA $\left(0.62 \mathrm{~m}^{2} / \mathrm{g}\right)$ was obtained with a non-severe 
milling condition $(0.26 \mathrm{~kJ} / \mathrm{g}$, equivalent to 5.4 minutes at $400 \mathrm{rpm})$; this represents an increase of $114 \%$ over the control. With further treatment SSA was decreased, anyway it never fell below the control value. A similar effect was found by Che, Li, Wang, Dong Chen, and Mao (2007) during pulverization of cassava starch in a vacuum ball-mill. These authors attributed the SSA reduction to a dynamic equilibrium between large particles crushing into smaller ones and tiny particles agglomerating. Agglomeration is favored by the great surface energies provided by the high impact milling.

In contrast to high-pressure treatment or ultra-sonication method (BeMiller, 2018; Błaszczak et al., 2007; Deka \& Sit, 2016; He et al., 2014; Mohammad Amini, Razavi, \& Mortazavi, 2015; Zhu, 2016) which are carried out with water as vapor or liquid media, the dry milling here proposed avoid the dehydration step to obtain powder starch. Ultrasonication as well as microwave or irradiation techniques (ref-1; Deka \& Sit, 2016; He et al., 2014) are emerging technologies still of high cost to be applied for starch modification at industrial scale.

\subsection{Energy - size relationships}

The significant effect of milling energy $(0-1.99 \mathrm{~kJ} / \mathrm{g})$ on particle size reduction can be observed in Figure 1. Generalized milling equation, with $c$ constant equal to 940.9 $\mathrm{kJ} /\left[\mathrm{mg}^{*} \mu \mathrm{m}^{(1-\mathrm{n})}\right]$ and $n$ equal to 5.6 (dimensionless), is shown and the good agreement between the experimental values and those predicted by the Holmes' model $\left(\mathrm{R}^{2}=0.9635\right)$ can be also appreciated. It must be noted that by doing the regression by setting $n$ equal to 2, as established by the Rittinger model, the adjustment was less satisfactory $\left(R^{2}=0.7499\right)$. In order to have a good fit, only the energy values between 0 and $1.99 \mathrm{~kJ} / \mathrm{g}$ were considered 
for the regression analysis. At higher energies the model did not adjust due to the negligible decrease of particle size (asymptote of the curve).

This model assumes that the energy is proportional to the new surface created. Therefore, the deviation from the predicted values would indicate that part of the milling energy is lost due to heat dissipation phenomenon (Barbosa-Cánovas et al., 2005; Loubes, 2015; Rhodes, 2008).

Recently Loubes (2015) reported that the magnitude of heat dissipation in a planetary ball mill is dependent on rotation speed. Thus, by selecting a convenient speed, the thermal events were minimized to obtain, as a consequence, a linear relationship among energy and size reduction ratio. Shashidhar, Murthy, Girish, and Manohar (2013), who studied the hammer milling of coriander seeds, also found a linear $E-R_{r}$ dependence.

In this work, the occurrence of significant heat dissipation seems to be corroborated by the non-linear dependence $\left(\mathrm{R}^{2}=0.9805\right)$ that was found between the specific milling energy and the size reduction ratio:

$$
E=0.0047 \exp \left(1.036 R_{r}\right)
$$

In accordance with this result, Mohd Rozalli, Chin, and Yusof (2015) accounted an exponential E- $\mathrm{R}_{\mathrm{r}}$ relationship for milling of peanut using an ultra-high speed mill.

To conclude, the deviation from the Rittinger model or a non-linear $\mathrm{E}-\mathrm{R}_{\mathrm{r}}$ relationship can be considered as an evidence of the irreversible heat dissipation in high impact milling where the energy delivered to the jar's content is not exclusively used for the reduction of the particle size.

\subsection{Crystallinity}


The native and modified starches presented typical A-type crystalline patterns (Fig. 2) with diffraction peaks $(2 \theta)$ at $15^{\circ}, 17^{\circ}, 18^{\circ}$ and $23^{\circ}$; which are characteristic of cereal starches (Singh, Singh, Kaur, Singh Sodhi, \& Singh Gill, 2003; Zhang et al., 2010; Zobel, 1988). Xray peak intensities of samples diminished as the treatment energy rose. Starches treated at energies higher than $1.99 \mathrm{~kJ} / \mathrm{g}$ showed a diffuse pattern. This behavior reflects the decrease in the crystalline portion of the granules and the consequent increase of the amorphous fraction as the grinding progresses.

The crystallinity degree at different milling energies is also shown in Fig. 2. The CD of the control sample was $46 \%$. This value could be reduced by $30 \%$ with the lowest energy condition $(0.26 \mathrm{~kJ} / \mathrm{g})$ and $86 \%$ with the most drastic conditions $(1.99-4.08 \mathrm{~kJ} / \mathrm{g})$. The minimum CD reached was 6\%. From $1.99 \mathrm{~kJ} / \mathrm{g}$, no significant differences $(\mathrm{p}<0.05)$ were observed in the crystallinity. CD variation of modified starches was related to the grinding energy through a potential model $\left(\mathrm{CD} \%=12.47 \mathrm{E}^{-0.624} ; \mathrm{R}^{2}=0.9657\right)$.

These results indicated that dry milling in the planetary ball mill was able to generate different degrees of change in rice starch structure, depending on the severity of the treatment. In agreement with Martínez-Bustos, López-Soto, San Martín-Martínez, ZazuetaMorales, and Velez-Medina (2007), ball milling treatment induced to spatial disorder of amylopectin and amylose, caused by a rise in the temperature due to conduction or dissipation of the mechanical energy during ball milling.

\subsection{Thermal properties}

Table 1 shows the values of the gelatinization parameters, peak temperature and enthalpy of gelatinization, of rice starch samples subjected to different milling energies. All the samples 
showed thermograms with a single endothermic peak, characteristic of gelatinization processes with a high water content (Biliaderis, Maurice, \& Vose, 1980).

The crystallinity degree and the proportion of amylose and amylopectin chains influence the gelatinization temperature. Gelatinization temperature is an important property to be determined in cereals, because it is strongly related to the cooking time and the final texture of the cooked products (Champagne, 2004). As it can be seen in Table 1, Tp values suffered a shift towards lower temperatures as milling progressed. This trend was also found by J.-J. Chen, Lii, and Lu (2003), Huang, Xie, Chen, Lu, and Tong (2008), María A. Loubes and Tolaba (2014) and Roa (2015) when performing mechanical treatments by grinding rice starch, cassava and corn starch, rice flour and amaranth flour; respectively.

As explained by Singh et al. (2003), differences in transition temperatures can be associated with the difference in the crystallinity degree of the samples. High transition temperatures are attributed to a high degree of crystallinity, which provides the granule structural stability and makes it more resistant to gelatinization. It is in agreement with the correlation found $(r=-0.9820 ; p<0.01)$ between $\Delta H$ and $C D$.

$\Delta \mathrm{H}$ values were reduced from $11.57 \mathrm{~J} / \mathrm{g}$ (native starch) to $1.53 \mathrm{~J} / \mathrm{g}$ for the sample treated at $0.54 \mathrm{~kJ} / \mathrm{g}$. These results evidence that the crystalline structure and the double helix structure of the rice starch were damaged by the mechanical treatment (Han, Chang, \& Kim, 2007; Martínez-Bustos et al., 2007), since $\Delta \mathrm{H}$ is a general measure of crystallinity and it is an indicator of the loss of molecular order within the granule (Singh et al., 2003). From 1.04 $\mathrm{kJ} / \mathrm{g}$ onwards no endothermic peaks were detected and it was found, therefore, that the starch samples were completely gelatinized.

The results show that the mechanical modification by grinding allows converting the structure of the starch from a semi-crystalline state to an amorphous state. It generates a 
decrease in the values of gelatinization enthalpy and peak temperature, without the need to add water and to dry the product later, taking advantage of hydrothermal pre-gelatinization treatments.

Unlike extrusion cooking, where the complete gelatinization of starch occurred (Hagenimana, Ding, \& Fang, 2006; Menegassi, Pilosof, \& Arêas, 2011) high impact ball milling can produce starch with slight or severe thermal damage, partial or total loss of crystallinity (amorphous starch). By means of adequate process conditions and milling protocol the degree of starch modification could be well controlled.

\subsection{Hydration properties}

WSI and SP indexes, for the different milling energy and temperature conditions of the hydration test are shown in Table 2. Dry-milling led to a significant increase in water hydration properties of rice starch. WSI and SP values of milled starches were always higher than those of the native starch, at the same temperature. The highest values corresponded to the most severe grinding condition in all the tests. For the highest energy and temperature levels $\left(4.08 \mathrm{~kJ} / \mathrm{g}\right.$ and $\left.85^{\circ} \mathrm{C}\right)$, the WSI value varied between $0.07-29.70 \%$ and SP between 2.12- $16.38 \mathrm{~g} / \mathrm{g}$ in comparison with the control at the lowest temperature $(0$ $\mathrm{kJ} / \mathrm{g}$ and $55^{\circ} \mathrm{C}$ ). For energies greater than $1.99 \mathrm{~kJ} / \mathrm{g}$ changes in $\mathrm{SP}$ were comparatively lower than those observed in the range $0-1.99 \mathrm{~kJ} / \mathrm{g}$. A non-linear SP-E relationship was accounted (not shown). In contrast, a linear relationship between WSI and E $\left(R^{2}>0.97\right)$ were found for all temperatures tested. Moreover, an increase in the hydration properties was observed with the increase of the test temperature at a fixed grinding energy. The highest WSI and SP values were found at the highest test temperature $\left(85^{\circ} \mathrm{C}\right)$. The 
information obtained on the hydration properties can be useful at the time of designing a grinding treatment to obtain starches for specific applications.

The hydration behavior of modified rice starches demonstrated a close relationship with the integrity and crystallinity of starch granules, in agreement with literature reports (C.-J. Chen, Shen, \& Yeh, 2010; Chiang \& Yeh, 2002; Devi, Fibrianto, Torley, \& Bhandari, 2009; He et al., 2014). As shown in Figure 3 (a and b), CD showed a negative exponential relationship $\left(\mathrm{R}^{2}>0.9\right)$ with solubility and a negative linear relationship $\left(\mathrm{R}^{2}>0.9\right)$ with SP. From these results, it can be inferred that increasing the proportion of the amorphous phase (greater disorder), facilitates water intake and its interaction with the polymer chains, favoring the solubility of the starch granules in water and promoting their swelling capacity.

\subsection{Pasting properties}

The RVA records and parameters of native and mechanically activated rice starches are shown in Fig. 4 and Table 3, respectively.

The pasting properties of modified rice starches were significantly affected $(p<0.05)$ by milling energy. When the mechanical activation increased, PT, PV, BD, TV, SB and FV values decreased, which was similar to several literature reports concerning to different milling techniques applied to rice starch (J.-J. Chen et al., 2003; Devi et al., 2009; Zhang et al., 2010). Significant correlations $(\mathrm{p}<0.01)$ between milling energy and PV $(r=-0,9161)$, BD $(r=-0,9869)$, TV $(r=-0,8709)$, SB $(r=-0,9420)$ and FV $(r=-0,9059)$ were found. 
394

395

396

397

398

399

400

401

402

403

404

405

406

407

408

409

410

411

412

413

414

415

416

physicochemical properties of rice starch, under the selected conditions of rotational speed and milling energy.

Pasting temperature of native rice starch in the present study $\left(79.1^{\circ} \mathrm{C} \pm 0,1^{\circ} \mathrm{C}\right)$ is within the reported range $\left(63.80^{\circ} \mathrm{C}\right.$ to $\left.95.10^{\circ} \mathrm{C}\right)$ for rice starches isolated from non-waxy rice varieties (Wani et al., 2012). In comparison with control (native starch), rice starches processed with milling energies within 0.52 and $1.99 \mathrm{~kJ} / \mathrm{g}$ showed lower values of pasting temperature $\left(70.6^{\circ} \mathrm{C}-76.2^{\circ} \mathrm{C}\right)$. Modified starches can swell and absorb water more rapidly than native starch, promoting starch gelatinization and the increase of viscosity at lower temperature (Asmeda, Noorlaila, \& Norziah, 2016; Tan et al., 2015). In contrast, between 2.63 and 4.08 $\mathrm{kJ} / \mathrm{g}$, PT values were higher $\left(84.8-94.0^{\circ} \mathrm{C}\right)$ than that of control. A similar result was found by Barrera et al. (2013) who detected an increase in PT records for wheat starch processed in a disk mill, relative to native starch.

Peak viscosity reflects the water retention capacity of starch granules. Starches pulverized in the planetary ball mil presented PV values within $544-3627 \mathrm{mPa} . \mathrm{s}$; these values were lower than that of native starch (4387 Pa.s). By increasing the content of damaged starch, the starch acquires less resistance to the swelling of the granules, resulting in smaller PV (Asmeda, Noorlaila, \& Norziah, 2016).

No differences were found among BD values of native starch and starches modified with energies within $0.26-0.52 \mathrm{~kJ} / \mathrm{g}$. This result evidenced a cooking behavior similar to control sample for these modified rice starches. Good palatability and quality during cooking are strongly associated to high values of BD (Kesarwani, Chiang, \& Chen, 2016). Thus, according to this criterion, the best results in the present work were those obtained at low milling energies. 
During cooling step, a new increment in apparent viscosity called setback viscosity $(70-$ $229 \%$ respect to TV) took place as result of retrogradation tendency of amylose chains. SB is an useful parameter related to the texture of the final product (Wani et al., 2012). FV indicates the starch capacity to form a viscous paste after being cooked and cooled. Modified starches showed values of FV within $526 \pm 42 \mathrm{mPa} . \mathrm{s}$ and $4792 \pm 46 \mathrm{mPa} . \mathrm{s}$, such values were significantly lower than that of native starch $(5764 \pm 46 \mathrm{mPa}$.s). For control sample and starches processed between 0.26 and $1.5 \mathrm{~kJ} / \mathrm{g}$ the values of FV were higher than those of $\mathrm{PV}$, and the increments were in the range 23 to $31 \%$. In contrast, the value of FV was slightly lower than that of PV (reduction of $1-3 \%$ ) in the case of modified starches at $1.99-4.08 \mathrm{~kJ} / \mathrm{g}$. Hossen et al. (2011) also obtained FV values higher than PV and a reduction in final viscosity values by increasing the milling severity during rice starch grinding using a co-jet mill. These authors attributed the reduction to the small particles that lose the ability to form gels after being cooked and cooled.

\subsection{Effect of particle size reduction on pasting properties}

Peak and setback viscosity as well as final viscosity presented a linear relationship $\left(\mathrm{R}^{2}>\right.$ 0,92) with median particle size $\left(\mathrm{D}_{50}\right)($ Fig. 5$)$.

A significant and positive correlation was found between PV and D50 $(r=0.87 ; \mathrm{p}<0.01)$ for modified starches; the linear relationship among the mentioned variables revealed that size reduction is associated to decrease of viscosity. The same behavior was found by Hossen et al. (2011) for starches from different sources, including rice starch. According with Tan et al. (2015), the viscosity loss is due to the small size of swelled granule. In the 
present work, $\mathrm{D}_{50}$ of modifies rice starches also presented a significant correlation with $\mathrm{SB}$ $(r=0.84 ; p<0.01)$ and with FV $(r=0.89 ; p<0.01)$

It must be noted that these relationships are confined within 0.26 and $1.99 \mathrm{~kJ} / \mathrm{g}$. At higher levels of milling energy nonlinear relationships were obtained (not shown) due to the asymptotic tendency of $\mathrm{D}_{50}$ as the milling severity increased.

\subsection{Correlations between structural and functional properties}

The Pearson coefficient varies from 1 to -1 ; it is a measure of the tendency of two variables to decrease or increase together. A correlation coefficient of zero means to have two independent variables. Based on coefficients from Pearson matrix, it was found the following significant correlations $(\mathrm{p}<0.01)$ for modified starches $(\mathrm{E}=0.26-4.08 \mathrm{~kJ} / \mathrm{g})$ :
(a)
Crystallinity - hydration properties at $85^{\circ} \mathrm{C}$
$\mathrm{C}: \mathrm{CD}-\mathrm{WSI}(\mathrm{r}=-0.76), \mathrm{CD}-\mathrm{SP}(\mathrm{r}=-0.95)$

Hydration capacity enhanced with crystallinity degree decreasing.

(b) Crystallinity - pasting properties: CD-PV $(r=0.95)$, CD-SB $(r=0.92)$, CD-FV $(r=$ $0.95)$.

The ability of modified starches to form paste diminished as crystallinity decreased.

(c) Thermal - pasting or hydration properties at $85^{\circ} \mathrm{C}: \Delta \mathrm{H}-\mathrm{PV}(\mathrm{r}=0.82), \Delta \mathrm{H}-\mathrm{SB}(\mathrm{r}=$ $0.75), \Delta \mathrm{H}-\mathrm{FV}(\mathrm{r}=0.82), \Delta \mathrm{H}-\mathrm{SP}(\mathrm{r}=-0.86)$.

As gelatinization degree of modified starches increased the aptitude to form paste decreased.

(d) Particle size - hydration properties at $85^{\circ} \mathrm{C}$ : $\mathrm{D}_{50}$-WSI $(\mathrm{r}=-0.96$; for the energy range of $0.26-1.99 \mathrm{~kJ} / \mathrm{g}), \mathrm{D}_{50}-\mathrm{SP}(\mathrm{r}=-0.97)$, SSA-WSI $(\mathrm{r}=-0.89)$, SSA-SP $(\mathrm{r}=-0.82)$. 
A reduction of particle size favored the hydration of starch particles. However, this result cannot be attributed to the increase of specific surface area due to SSA was increasing only within $0-0.26 \mathrm{~kJ} / \mathrm{g}$ energy range, as discussed in section 3.2 .

(e) Particle size - pasting properties: D50-PV $(r=0.87)$, D50-SB $(r=0.84)$, D50-FV $(r$ $=0.89)$, SSA-PV $(r=0.92)$, SSA-SB $(r=0.88)$, SSA-FV $(r=0.91)$.

Size reduction can be associated to decrease of viscosity. A detailed discussion was presented in section 3.7 .

\section{CONCLUSIONS}

This work showed that dry milling in a planetary ball mill is especially suitable to produce structural changes in rice starch, which significantly affect its behavior. It was possible to modify the physicochemical and functional properties of the native rice starch, without the generation of waste products during the process. However, planetary ball mills are now available only at laboratory-scale. Further research will be required for scaling starch milling using industrial-scale equipment.

The proposed method was effective to reduce both particle size and size dispersion as well as to increase the specific surface area of starch samples. Pasting properties of modified starches showed significant differences in comparison with native rice starch, even those samples processed at low milling energies. However, no significant effect of milling energy on pasting parameters was detected above $3.56 \mathrm{~kJ} / \mathrm{g}$ and $4.08 \mathrm{~kJ} / \mathrm{g}$. It was also possible to obtain amorphous starch and starch with different crystallinity degrees by the appropriate selection of grinding conditions.

By increasing the severity of the milling treatment and the temperature of the hydration tests the hydration properties increased. The higher absorption capacity and solubility in water presented by the modified starches in relation to the control, give them distinctive characteristics to perform cooking and sensorial attributes of bread and pasta products. 
In accordance to RVA tests, the modified rice starch, despite of its poor capacity to form paste, could be applied to produce starch gels for starch-thickened sauces.

As a result of its fine granulometry, modified rice starch has a mouth feel similar to fat globule and therefore it could be used as fat-replacer in low-fat foods. Due to its high solubility, it could facilitate the elaboration of homogeneous and viscous liquid suspensions which are valued in liquid food formulations.

In summary, rice starch treatment by planetary ball mill, allow modifications of several structural and functional characteristics that extend their possible applications in the cosmetic, pharmaceutical and food industry.

\section{ACKNOWLEDGMENTS}

The authors acknowledge the financial support from Buenos Aires University and National Council of Scientific Research of Argentine. This work has been funded by PME-2006-01685 and UBACYT (Project UBACYT 20020130100442BA).

\section{REFERENCES}

Alcázar-Alay, S. C., \& Meireles, M. A. A. (2015). Physicochemical properties, modifications and applications of starches from different botanical sources. Food Science and Technology, 35, 215-236.

AOAC. (2000). Solids (total) and moisture in flour. Official Methods of Analysis (17th ed.). Gaithersburg, MD: Association of Official Analytical Chemists.

Ashogbon, A. O., \& Akintayo, E. T. (2014). Recent trend in the physical and chemical modification of starches from different botanical sources: A review. Starch - Stärke, 66(1-2), 41-57. doi: 10.1002/star.201300106

Asmeda, R., Noorlaila, A., \& Norziah, M. H. (2016). Relationships of damaged starch granules and particle size distribution with pasting and thermal profiles of milled MR263 rice flour. Food Chemistry, 191, 45-51. doi: http://dx.doi.org/10.1016/j.foodchem.2015.05.095 
Barbosa-Cánovas, G. V., Ortega-Rivas, E., Juliano, P., \& Yan, H. (2005). Food Powders: Physical Properties, Processing, and Functionality ( $1^{\circ} \mathrm{Ed}$ ed.). Nueva York: Kluwer academic/Plenum Publishers.

Barrera, G. N., Bustos, M. C., Iturriaga, L., Flores, S. K., León, A. E., \& Ribotta, P. D. (2013). Effect of damaged starch on the rheological properties of wheat starch suspensions. Journal of Food Engineering, 116(1), 233-239. doi: http://dx.doi.org/10.1016/j.jfoodeng.2012.11.020

BeMiller, J. N. (2018). Chapter 5 - Physical Modification of Starch A2 - Sjöö, Malin. In L. Nilsson (Ed.), Starch in Food (Second Edition) (pp. 223-253): Woodhead Publishing.

Biliaderis, C. G., Maurice, T. J., \& Vose, J. R. (1980). STARCH GELATINIZATION PHENOMENA STUDIED BY DIFFERENTIAL SCANNING CALORIMETRY. Journal of Food Science, 45(6), 1669-1674. doi: 10.1111/j.1365-2621.1980.tb07586.x

Błaszczak, W., Fornal, J., Kiseleva, V. I., Yuryev, V. P., Sergeev, A. I., \& Sadowska, J. (2007). Effect of high pressure on thermal, structural and osmotic properties of waxy maize and Hylon VII starch blends. Carbohydrate Polymers, 68(3), 387-396. doi: http://dx.doi.org/10.1016/j.carbpol.2006.12.023

Champagne, E. T. (2004). Rice: chemistry and technology: American Association of Cereal Chemists.

Che, L.-M., Li, D., Wang, L.-J., Dong Chen, X., \& Mao, Z.-H. (2007). Micronization and Hydrophobic Modification of Cassava Starch. International Journal of Food Properties, 10(3), 527-536. doi: 10.1080/10942910600932982

Chen, C.-J., Shen, Y.-C., \& Yeh, A.-I. (2010). Physico-chemical characteristics of media-milled corn starch. J Agric Food Chem, 58(16), 9083-9091.

Chen, J.-J., Lii, C.-Y., \& Lu, S. (2003). Physicochemical and Morphological Analyses on Damaged Rice Starches. Journal of Food and Drug Analysis, 11(4), 283-289.

Chiang, P. Y., \& Yeh, A. I. (2002). Effect of Soaking on Wet-milling of Rice. Journal of Cereal Science, 35(1), 85-94. doi: http://dx.doi.org/10.1006/jcrs.2001.0419

Deka, D., \& Sit, N. (2016). Dual modification of taro starch by microwave and other heat moisture treatments. International Journal of Biological Macromolecules, 92, 416-422. doi: http://dx.doi.org/10.1016/j.ijbiomac.2016.07.040 
Devi, A. F., Fibrianto, K., Torley, P. J., \& Bhandari, B. (2009). Physical properties of cryomilled rice starch. Journal of Cereal Science, 49(2), 278-284. doi: http://doi.org/10.1016/j.jcs.2008.11.005

Guerzoni, M. E., Gianotti, A., \& Vernocchi, P. (2011). Chapter 34 - Effect of Starch Addition to Fluid Dough During the Bread Making Process A2 - Preedy, Victor R. In R. R. Watson \& V. B. Patel (Eds.), Flour and Breads and their Fortification in Health and Disease Prevention (pp. 375-384). San Diego: Academic Press.

Hagenimana, A., Ding, X., \& Fang, T. (2006). Evaluation of rice flour modified by extrusion cooking. Journal of Cereal Science, 43(1), 38-46. doi: https://doi.org/10.1016/j.jcs.2005.09.003

Han, M.-R., Chang, M.-J., \& Kim, M.-H. (2007). Changes in physicochemical properties of rice starch processed by ultra-fine pulverization. Journal of Applied Biological Chemistry, 50(4), 234-238.

He, S., Qin, Y., Walid, E., Li, L., Cui, J., \& Ma, Y. (2014). Effect of ball-milling on the physicochemical properties of maize starch. Biotechnology Reports, 3, 54-59. doi: http://dx.doi.org/10.1016/j.btre.2014.06.004

Holmes, J. A. (1957). A contribution to the study of comminution. Amodified form of Kick's law. Trans. Inst. Chem. Engrs. (London), 35, 125-141.

Hossen, M. S., Sotome, I., Takenaka, M., Isobe, S., Nakajima, M., \& Okadome, H. (2011). Effect of Particle Size of Different Crop Starches and Their Flours on Pasting Properties. Japan Journal of Food Engineering, 12(1), 29-35.

Huang, Z.-Q., Xie, X.-1., Chen, Y., Lu, J.-p., \& Tong, Z.-F. (2008). Ball-milling treatment effect on physicochemical properties and features for cassava and maize starches. Comptes Rendus Chimie, 11(1-2), 73-79. doi: http://dx.doi.org/10.1016/j.crci.2007.04.008

Kesarwani, A., Chiang, P. Y., \& Chen, S. S. (2016). Rapid Visco Analyzer Measurements of japonica Rice Cultivars to Study Interrelationship between Pasting Properties and Farming System. International Journal of Agronomy, 2016, 6. doi: 10.1155/2016/3595326

Li, G., Wang, S., \& Zhu, F. (2016). Physicochemical properties of quinoa starch. Carbohydrate Polymers, 137(Supplement C), 328-338. doi: https://doi.org/10.1016/j.carbpol.2015.10.064

Liu, T. Y., Ma, Y., Yu, S. F., Shi, J., \& Xue, S. (2011). The effect of ball milling treatment on structure and porosity of maize starch granule. Innovative Food Science \& Emerging Technologies, 12(4), 586-593. doi: http://dx.doi.org/10.1016/j.ifset.2011.06.009 
Loubes, M. A. (2015a). Dry and wet milling of rice in a planetary ball mill. Milling kinetics, effect of milling conditions on flour and starch functional properties and mixture design of gluten free pasta. (PhD Thesis), Industry Department, School of Exact and Natural Sciences, University of Buenos Aires, Argentina.

Loubes, M. A., \& Tolaba, M. P. (2014). Thermo-mechanical rice flour modification by planetary ball milling. LWT - Food Science and Technology, 57(1), 320-328. doi: http://dx.doi.org/10.1016/j.lwt.2013.12.048

Martínez-Bustos, F., López-Soto, M., San Martín-Martínez, E., Zazueta-Morales, J. J., \& VelezMedina, J. J. (2007). Effects of high energy milling on some functional properties of jicama starch (Pachyrrhizus erosus L. Urban) and cassava starch (Manihot esculenta Crantz). Journal of Food Engineering, 78(4), 1212-1220. doi: https://doi.org/10.1016/j.jfoodeng.2005.10.043

McCabe, W. L., Smith, J. C., \& Harriot, P. (2007). Operaciones Unitarias en Ingeniería Química ( $7^{\circ}$ Ed ed.). México: McGraw-Hill.

Menegassi, B., Pilosof, A. M. R., \& Arêas, J. A. G. (2011). Comparison of properties of native and extruded amaranth (Amaranthus cruentus L. - BRS Alegria) flour. LWT - Food Science and Technology, 44(9), 1915-1921. doi: https://doi.org/10.1016/j.lwt.2011.04.008

Mohammad Amini, A., Razavi, S. M. A., \& Mortazavi, S. A. (2015). Morphological, physicochemical, and viscoelastic properties of sonicated corn starch. Carbohydrate Polymers, 122, 282-292. doi: https://doi.org/10.1016/j.carbpol.2015.01.020

Mohd Rozalli, N. H., Chin, N. L., \& Yusof, Y. A. (2015). Grinding characteristics of Asian originated peanuts (Arachishypogaea L.) and specific energy consumption during ultra-high speed grinding for natural peanut butter production. Journal of Food Engineering, 152(Supplement C), 1-7. doi: https://doi.org/10.1016/j.jfoodeng.2014.11.027

Retsch. (2009). Milling by planetary ball mill. Haan: Retsch GmbH.

Rhodes, M. (2008). Introduction to Particle Technology ( $2^{\circ}$ Ed ed.). Chichester: John Wiley \& Sons Ltd.

Roa, D. F. (2015). Métodos de molienda seca y húmeda en molino planetario para la obtención y caracterización de fracciones de amaranto y su aplicación como agente encapsulante. (Tesis Doctoral), Universidad de Buenos Aires.

Roa, D. F., Santagapita, P. R., Buera, M. P., \& Tolaba, M. P. (2014). Ball Milling of Amaranth Starch-Enriched Fraction. Changes on Particle Size, Starch Crystallinity, and Functionality 
as a Function of Milling Energy. Food and Bioprocess Technology, 7(9), 2723-2731. doi: 10.1007/s11947-014-1283-0

Shashidhar, M., Murthy, T. K., Girish, K. G., \& Manohar, B. (2013). Grinding of coriander seeds: modeling of particle size distribution and energy studies. Particulate Science and Technology, 31(5), 449-457.

Singh, N., Singh, J., Kaur, L., Singh Sodhi, N., \& Singh Gill, B. (2003). Morphological, thermal and rheological properties of starches from different botanical sources. Food Chemistry, 81(2), 219-231. doi: https://doi.org/10.1016/S0308-8146(02)00416-8

Taggart, P. (2004). Starch as an ingredient: manufacture and applications. In A.-C. Eliasson (Ed.), Starch in Food: Structure, Function and Applications ( $1^{\text {ra }}$ ed. ed., pp. 363-392). Cambridge: Woodhead Publishing.

Tan, X., Zhang, B., Chen, L., Li, X., Li, L., \& Xie, F. (2015), Effect of planetary ball-milling on multi-scale structures and pasting properties of waxy and high-amylose cornstarches. Innovative Food Science \& Emerging Technologies, 30, 198-207. doi: http://dx.doi.org/10.1016/j.ifset.2015.03.013

Wani, A. A., Singh, P., Shah, M. A., Schweiggert-Weisz, U., Gul, K., \& Wani, I. A. (2012). Rice Starch Diversity: Effects on Structural, Morphological, Thermal, and Physicochemical Properties-A Review. Comprehensive Reviews in Food Science and Food Safety, 11(5), 417-436. doi: 10.1111/j.1541-4337.2012.00193.x

Zhang, Z., Zhao, S., \& Xiong, S. (2010). Morphology and physicochemical properties of mechanically activated rice starch. Carbohydrate Polymers, 79(2), 341-348. doi: http://dx.doi.org/10.1016/j.carbpol.2009.08.016

Zhu, F. (2016). Impact of $\gamma$-irradiation on structure, physicochemical properties, and applications of starch. Food Hydrocolloids, 52, 201-212. doi: http://dx.doi.org/10.1016/j.foodhyd.2015.05.035

Zobel, H. F. (1988). Starch crystal transformations and their industrial importance. Starch, 4O(1), 17.

\section{WEB REFERENCES}

Technics and Technology of Disintegration Co. (2015). Planetary mills. www.ttd.spb.ru. Last access: 5th February 2018. 
638

639

640

641

642

643

644

645

646

647

648

649

650

651

652

653

654

655

656

657

658

659

660

\section{Figure captions}

Figure 1: relationship between grinding energy and particle diameter D50. ( $\square)$ :

experimental data, (-): predicted by the generalized Holmes' equation, (-): predicted by the Rittinger model.

Figure 2. Spectra of X-ray diffraction and crystallinity degree (CD) of control and modified rice starches, depending on the specific energy of grinding.

Figure 3. Relationship between the crystallinity degree $(\mathrm{CD}, \%)$ and a) the water solubility index (WSI, \%), b) the swelling power (SP, g/g); depending on the temperature of the hydration test.

a) $\mathbf{5 5}^{\circ} \mathbf{C}:$ WSI $=191.81 \mathrm{CD}^{1.19} ; \mathbf{6 5}^{\circ} \mathbf{C}: \mathrm{WSI}=176.29 \mathrm{CD}^{1.17} ; \mathbf{7 5}^{\circ} \mathbf{C}: \mathrm{WSI}=126.41 \mathrm{CD}^{0.92}$;

$\mathbf{8 5}^{\circ} \mathbf{C}$ : WSI $=125.31 \mathrm{CD}^{0.89}$

b) $\mathbf{5 5}^{\circ} \mathrm{C}: \mathrm{SP}=-0.25 \mathrm{CD}+11.33 ; \mathbf{6 5}^{\circ} \mathbf{C}: \mathrm{SP}=-0.27 \mathrm{CD}+13.06$;

$\mathbf{7 5}^{\circ} \mathrm{C}: \mathrm{SP}=-0.16 \mathrm{CD}+14.56 ; \mathbf{8 5}^{\circ} \mathrm{C}: \mathrm{SP}=-0.16 \mathrm{CD}+17.54$

Figure 4. RVA viscosity profile of native starch (control, $0 \mathrm{~kJ} / \mathrm{g}$ ) and modified rice starches as function of milling energy.

Figure 5. Linear relationships between starch pasting viscosities (PV, SB y VF) and particle size $\left(\mathrm{D}_{50}\right)$.

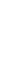




\section{Particle size distribution}

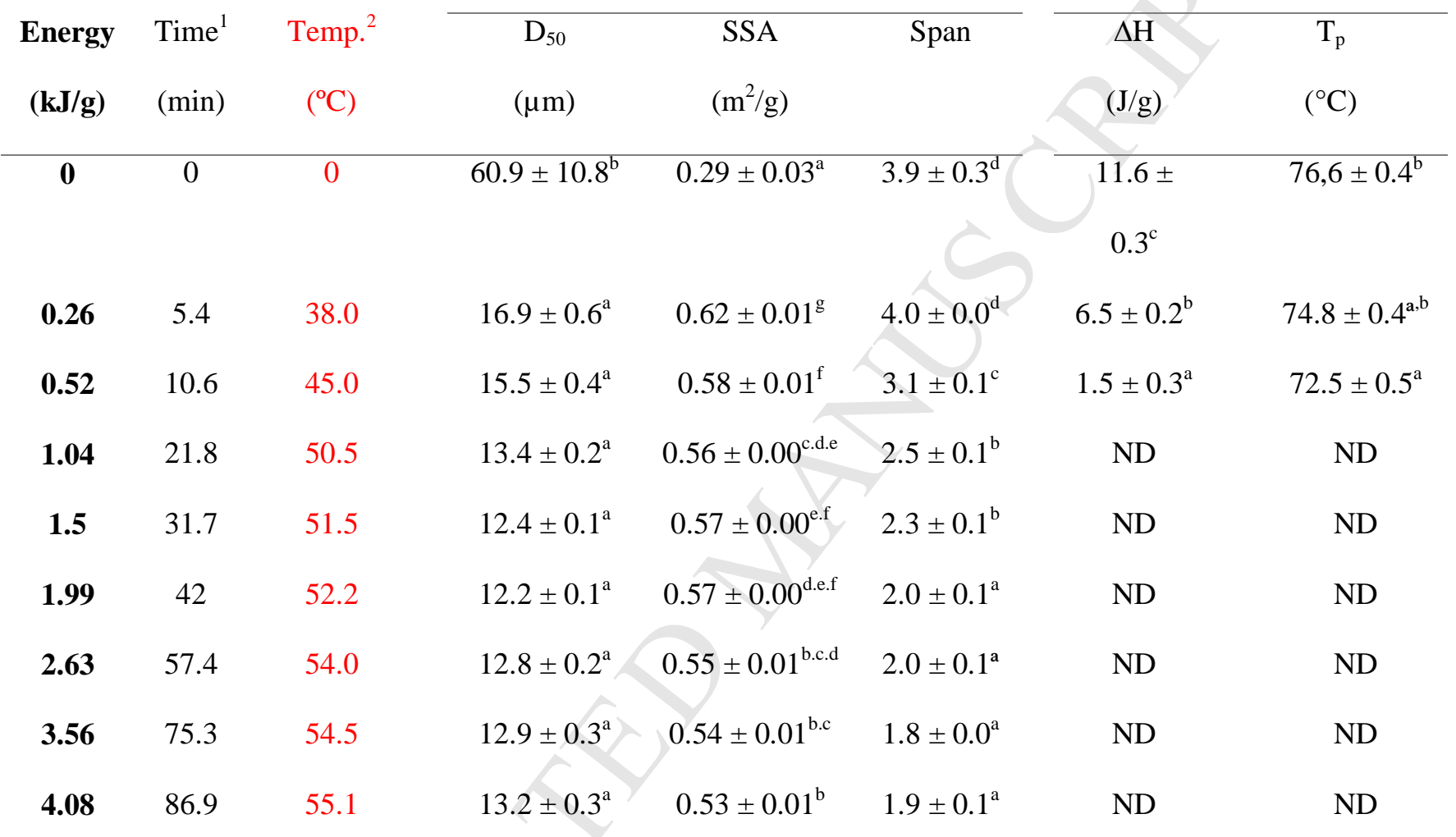

\section{Thermal properties}

$\Delta \mathrm{H} \quad \mathrm{T}_{\mathrm{p}}$ 
675

676 Table 2: Water solubility index (WSI) and swelling power (SP) of native and modified rice

677 starches, depending on the specific milling energy (E) and the test temperature.

678

\begin{tabular}{|c|c|c|c|c|c|c|c|c|}
\hline \multirow{3}{*}{$\begin{array}{c}E \\
(\mathrm{~kJ} / \mathrm{g})\end{array}$} & \multicolumn{4}{|c|}{ Water solubility index $(\%)$} & \multicolumn{4}{|c|}{ Swelling power $(\mathrm{g} / \mathrm{g})$} \\
\hline & WSI & WSI & WSI & WSI & $\mathbf{S P}$ & 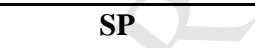 & $\mathbf{S P}$ & $\mathbf{S P}$ \\
\hline & $55^{\circ} \mathrm{C}$ & $65^{\circ} \mathrm{C}$ & $7^{\circ} \mathrm{C}$ & $8^{\circ} \mathrm{C}$ & $5^{\circ} \mathrm{C}$ & $65^{\circ} \mathrm{C}$ & $7^{\circ} \mathrm{C}$ & $8^{\circ} \mathrm{C}$ \\
\hline $\mathbf{0}$ & $0.07 \pm 0.00^{\mathrm{a}, 1}$ & $0.94 \pm 0.19^{\mathrm{a}, 2}$ & $1.28 \pm 0.24^{\mathrm{a}, 3}$ & $1.54 \pm 0.05^{\mathrm{a}, 3}$ & $2.12 \pm 0.05^{\mathrm{a}, 1}$ & $2.61 \pm 0.05^{\mathrm{a}, 2}$ & $5.97 \pm 0.13^{\mathrm{a}, 3}$ & $7.43 \pm 0.13^{\mathrm{a}, 4}$ \\
\hline 0.26 & $3.32 \pm 0.16^{\mathrm{b}, 1}$ & $4.19 \pm 0.08^{\mathrm{b}, 2}$ & $5.93 \pm 0.24^{\mathrm{b}, 3}$ & $6.42 \pm 0.03^{\mathrm{b}, 4}$ & $3.74 \pm 0.06^{\mathrm{b}, 1}$ & $5.10 \pm 0.23^{\mathrm{b}, 2}$ & $9.83 \pm 0.11^{\mathrm{b}, 3}$ & $12.72 \pm 0.50^{\mathrm{b}, 4}$ \\
\hline 0.52 & $5.68 \pm 0.03^{\mathrm{c}, 1}$ & $4.16 \pm 0.31^{\mathrm{b}, 1}$ & $7.86 \pm 0.30^{\mathrm{c}, 2}$ & $8.58 \pm 0.29^{\mathrm{c}, 2}$ & $5.69 \pm 0.10^{\mathrm{c}, 1}$ & $6.79 \pm 0.53^{\mathrm{c}, 2}$ & $10.59 \pm 0.33^{c, 3}$ & $13.46 \pm 0.84^{\mathrm{b}, 4}$ \\
\hline 1.04 & $10.04 \pm 0.14^{\mathrm{d}, 2}$ & $8.76 \pm 1.00^{\mathrm{c}, 1}$ & $11.79 \pm 0.25^{\mathrm{d}, 3}$ & $13.13 \pm 0.11^{\mathrm{d}, 4}$ & $8.03 \pm 0.08^{\mathrm{d}, 1}$ & $9.35 \pm 0.37^{\mathrm{d}, 2}$ & $12.29 \pm 0.13^{\mathrm{d}, 3}$ & $15.92 \pm 0.42^{\mathrm{c}, 4}$ \\
\hline 1.50 & $12.54 \pm 0.46^{\mathrm{e}, 1}$ & $13.01 \pm 0.14^{\mathrm{d}, 1}$ & $14.77 \pm 0.78^{\mathrm{e}, 2}$ & $15.09 \pm 0.53^{\mathrm{e}, 2}$ & $8.87 \pm 0.02^{\mathrm{e}, 1}$ & $10.39 \pm 0.12^{\mathrm{d}, \mathrm{e}, 2}$ & $12.42 \pm 0.06^{\mathrm{d}, 3}$ & $16.80 \pm 0.40^{\mathrm{d}, 4}$ \\
\hline 1.99 & $16.88 \pm 0.47^{\mathrm{f}, 1}$ & $15.93 \pm 1.38^{\mathrm{e}, 1}$ & $18.74 \pm 0.61^{\mathrm{f}, 2}$ & $19.22 \pm 0.47^{\mathrm{f}, 2}$ & $9.41 \pm 0.16^{\mathrm{f}, 1}$ & $10.92 \pm 0.67^{\mathrm{e}, \mathrm{f}, 2}$ & $13.49 \pm 0.17^{\mathrm{e}, 3}$ & $16.43 \pm 0.67^{\mathrm{c}, \mathrm{d}, 4}$ \\
\hline 2.63 & $20.41 \pm 0.11^{\mathrm{g}, 1}$ & $21.13 \pm 0.62^{\mathrm{f}, 1}$ & $22.78 \pm 0.62^{\mathrm{g}, 2}$ & $23.60 \pm 0.33^{\mathrm{g}, 2}$ & $9.89 \pm 0.14^{\mathrm{g}, 1}$ & $11.24 \pm 0.04^{\mathrm{e}, \mathrm{f}, 2}$ & $13.69 \pm 0.05^{\mathrm{e}, 3}$ & $16.42 \pm 0.31^{\mathrm{c}, \mathrm{d}, 4}$ \\
\hline 3.56 & $24.13 \pm 0.62^{\mathrm{h}, 1}$ & $24.63 \pm 0.59^{\mathrm{g}, 1}$ & $26.01 \pm 0.55^{\mathrm{h}, 2}$ & $28.20 \pm 0.30^{\mathrm{h}, 3}$ & $10.11 \pm 0.23^{\mathrm{g}, \mathrm{h}, 1}$ & $11.78 \pm 0.48^{\mathrm{e}, \mathrm{f}, 2}$ & $13.74 \pm 0.37^{\mathrm{e}, 3}$ & $17.08 \pm 0.26^{\mathrm{d}, 4}$ \\
\hline 4.08 & $26.36 \pm 0.30^{\mathrm{i}, 1}$ & $25.39 \pm 3.18^{\mathrm{g}, 1}$ & $29.08 \pm 0.08^{\mathrm{i}, 1,2}$ & $29.70 \pm 0.42^{\mathrm{i}, 2}$ & $10.28 \pm 0.14^{\mathrm{h}, 1}$ & $11.49 \pm 1.80^{\mathrm{f}, 1}$ & $13.93 \pm 0.91^{\mathrm{e}, 2}$ & $16.38 \pm 0.60^{\mathrm{c}, \mathrm{d}, 3}$ \\
\hline
\end{tabular}

679 Results are mean of three determinations \pm standard deviation.

680 The means in the columns with different letters in the superscript are significantly different from the grinding

681 energy $(p<0.05)$. The means in the rows with different numbers in the superscript are significantly different

682 from the treatment temperature $(p<0.05)$.

683

684

685

686

687

688

689 
691

692

Table 3. Pasting properties of rice starch as function of milling energy.

\begin{tabular}{|c|c|c|c|c|c|c|c|}
\hline $\begin{array}{c}E \\
(\mathrm{~kJ} / \mathrm{g})\end{array}$ & $\begin{array}{l}\text { PT } \\
\left({ }^{\circ} \mathrm{C}\right)\end{array}$ & $\begin{array}{c}\mathbf{P t} \\
(\mathrm{min})\end{array}$ & $\begin{array}{c}\text { PV } \\
\text { (mPa.s) }\end{array}$ & $\begin{array}{c}\text { BD } \\
\text { (mPa.s) }\end{array}$ & $\begin{array}{c}\text { TV } \\
\text { (mPa.s) }\end{array}$ & $\begin{array}{c}\text { SB } \\
\text { (mPa.s) }\end{array}$ & $\begin{array}{c}\mathbf{F V} \\
(\mathrm{mPa} . \mathrm{s})\end{array}$ \\
\hline 0 & $79.1 \pm 0.1^{\mathrm{d}}$ & $6.32 \pm 0.03^{\mathrm{e}}$ & $4384 \pm 17^{\mathrm{h}}$ & $1006 \pm 40^{\mathrm{e}}$ & $3378 \pm 43^{\mathrm{h}}$ & $2386 \pm 71^{g}$ & $5764 \pm 46^{h}$ \\
\hline 0.26 & $79.6 \pm 0.5^{\mathrm{d}}$ & $6.20 \pm 0.00^{\mathrm{e}}$ & $3627 \pm 12^{\mathrm{g}}$ & $981 \pm 26^{\mathrm{e}}$ & $2646 \pm 14^{\mathrm{g}}$ & $2146 \pm 38^{f}$ & $4792 \pm 24^{\mathrm{g}}$ \\
\hline 0.52 & $74.3 \pm 0.0^{\mathrm{b}}$ & $5.90 \pm 0.05^{\mathrm{d}}$ & $2995 \pm 15^{\mathrm{f}}$ & $1041 \pm 33^{\mathrm{e}}$ & $1954 \pm 18^{\mathrm{f}}$ & $1977 \pm 83^{\mathrm{e}}$ & $3931 \pm 65^{f}$ \\
\hline 1.04 & $70.2 \pm 0.1^{\mathrm{a}}$ & $5.50 \pm 0.14^{\mathrm{c}}$ & $1895 \pm 36^{\mathrm{e}}$ & $887 \pm 39^{d}$ & $1008 \pm 75^{\mathrm{e}}$ & $1325 \pm 20^{\mathrm{d}}$ & $2333 \pm 95^{\mathrm{e}}$ \\
\hline 1.50 & $70.6 \pm 1.7^{\mathrm{a}}$ & $5.40 \pm 0.09^{b . c}$ & $1646 \pm 141^{d}$ & $843 \pm 62^{d}$ & $803 \pm 79^{d}$ & $1144 \pm 107^{c}$ & $1947 \pm 28^{\mathrm{d}}$ \\
\hline 1.99 & $76.2 \pm 1.7^{c}$ & $5.33 \pm 0.09^{b}$ & $1235 \pm 49^{c}$ & $734 \pm 30^{c}$ & $501 \pm 18^{c}$ & $696 \pm 0^{\mathrm{b}}$ & $1197 \pm 18^{\mathrm{c}}$ \\
\hline 2.63 & $84.8 \pm 0.0^{\mathrm{e}}$ & $5.30 \pm 0.05^{\mathrm{a} . \mathrm{b}}$ & $913 \pm 9^{b}$ & $599 \pm 36^{\mathrm{b}}$ & $314 \pm 27^{b}$ & $571 \pm 4^{b}$ & $885 \pm 31^{\mathrm{b}}$ \\
\hline 3.56 & $93.6 \pm 1.1^{\mathrm{f}}$ & $5.27 \pm 0.09^{\mathrm{a} . \mathrm{b}}$ & $595 \pm 15^{\mathrm{a}}$ & $410 \pm 17^{\mathrm{a}}$ & $185 \pm 2^{\mathrm{a}}$ & $405 \pm 28^{\mathrm{a}}$ & $590 \pm 26^{\mathrm{a}}$ \\
\hline 4.08 & $94.0 \pm 0.6^{\mathrm{f}}$ & $5.17 \pm 0.05^{\mathrm{a}}$ & $544 \pm 19^{\mathrm{a}}$ & $384 \pm 16^{\mathrm{a}}$ & $160 \pm 4^{\mathrm{a}}$ & $366 \pm 38^{\mathrm{a}}$ & $526 \pm 42^{a}$ \\
\hline
\end{tabular}

695

696

697

698

699

700

701

702

703 


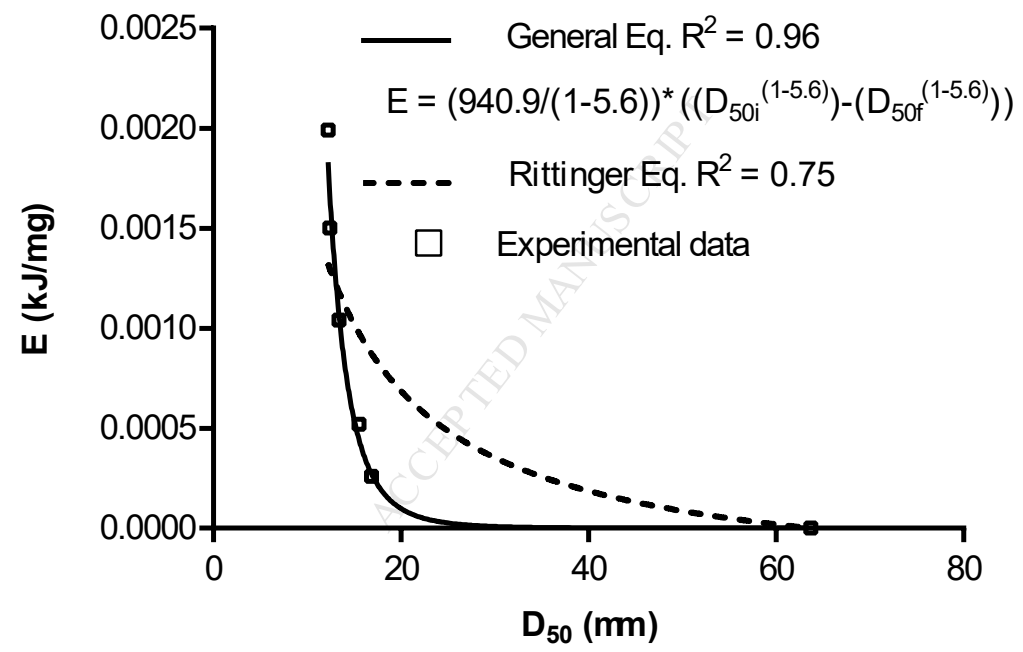




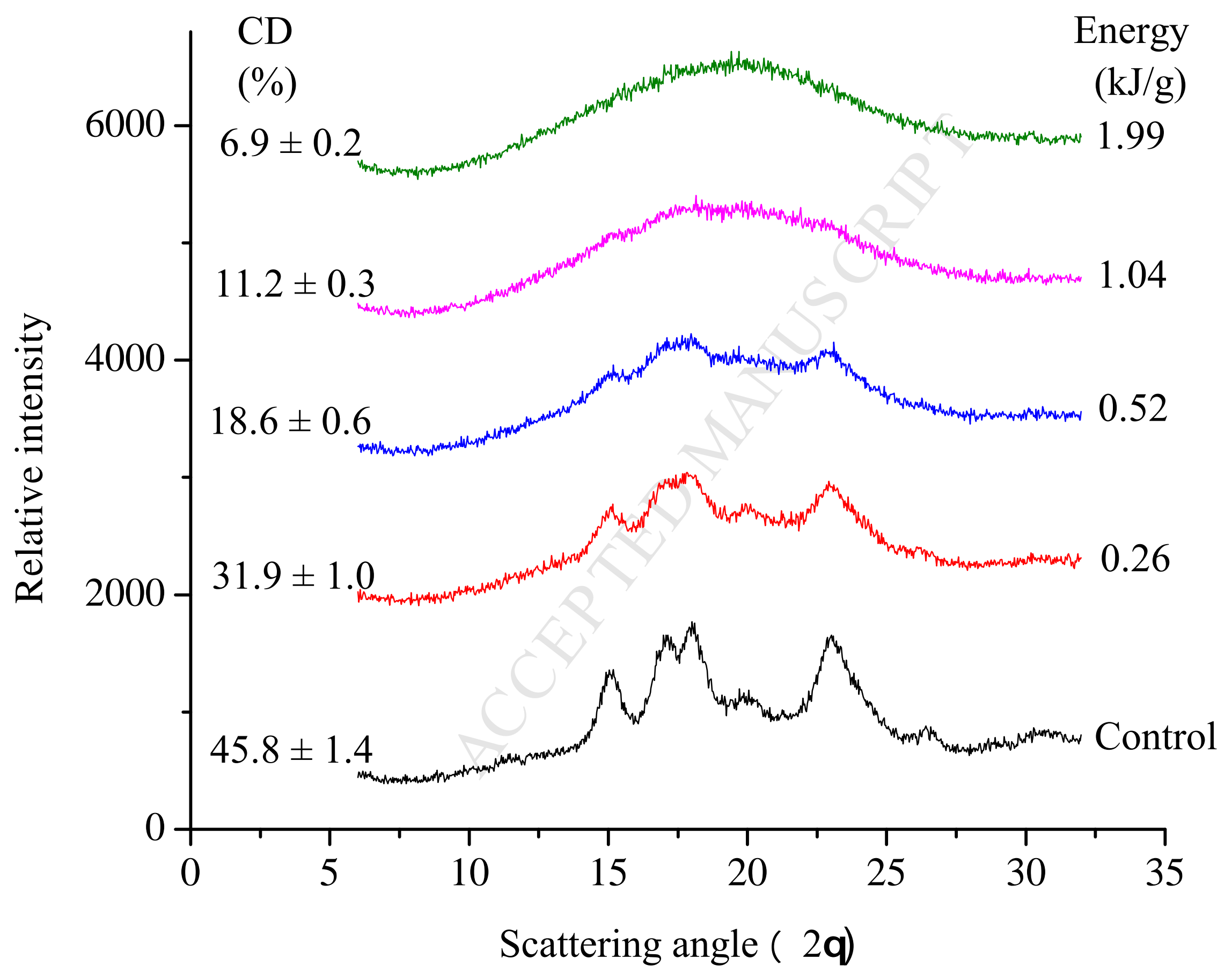




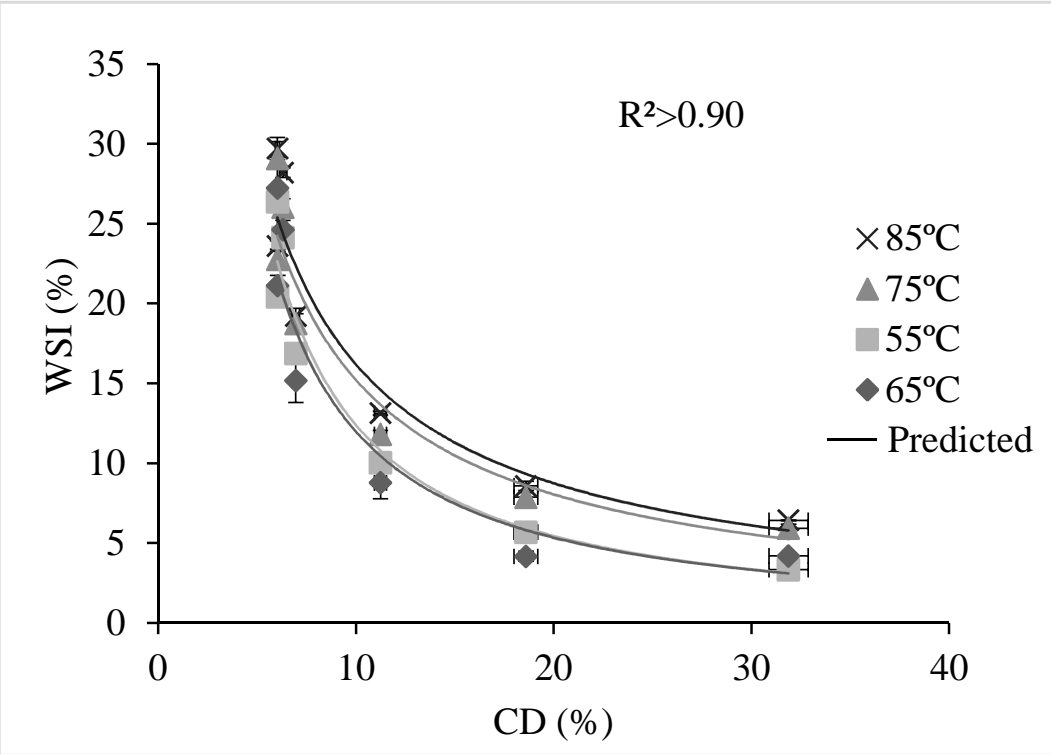




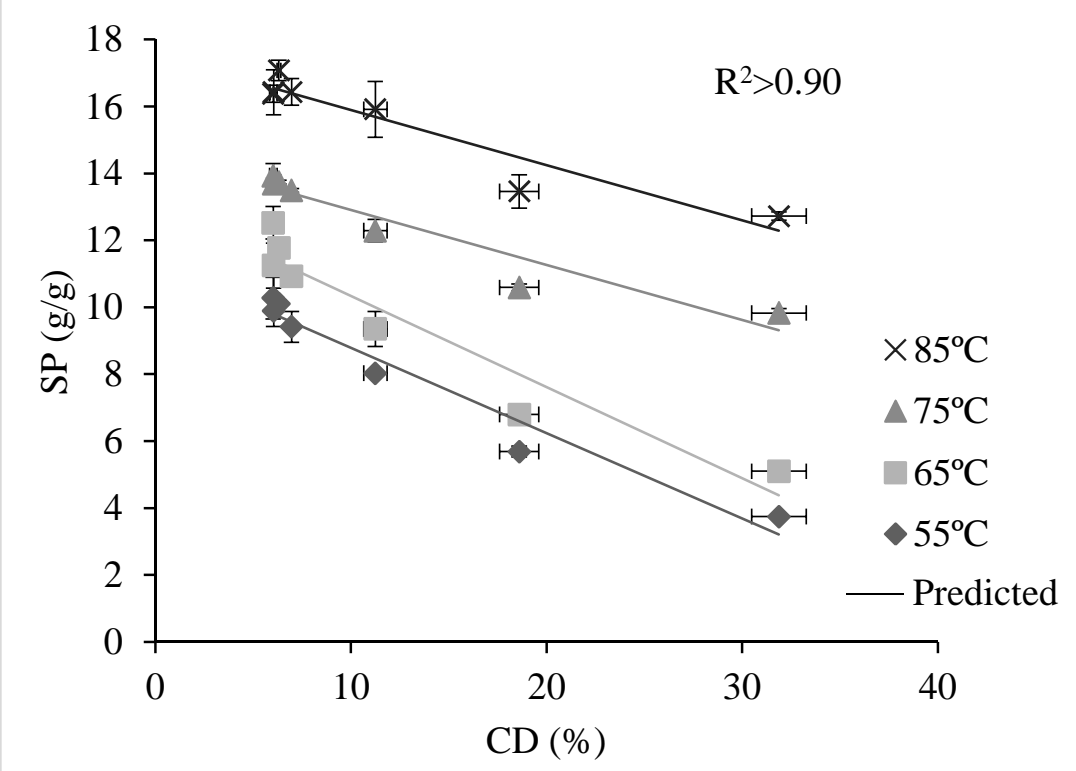




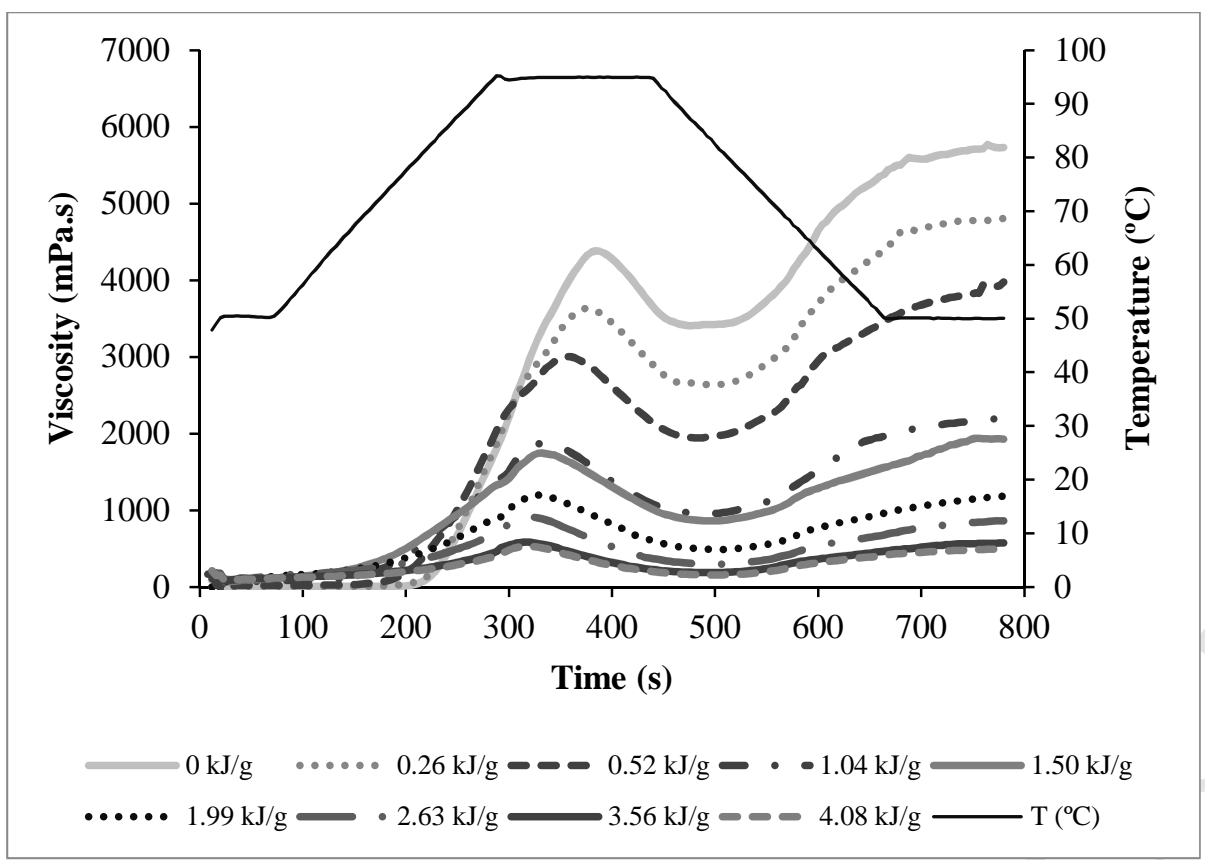




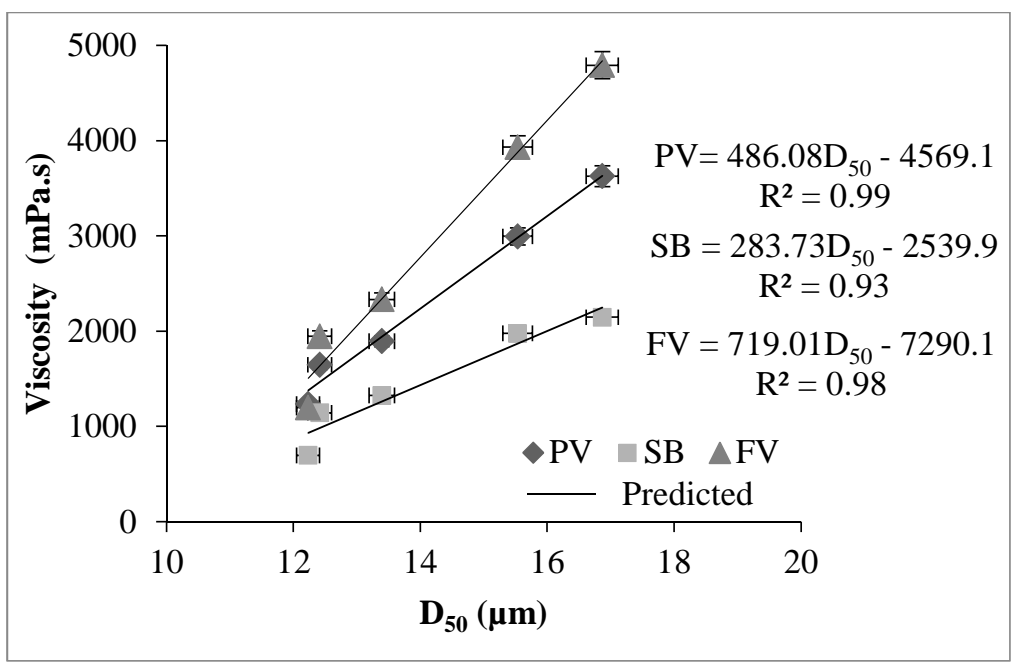




\section{Highlights}

1. Dry milling in planetary ball mill is proposed to modify rice starch properties.

32 2. Energy-size relationship was accurately predicted by Holmes' model.

43 . Energy was related to physicochemical and functional properties of starch.

5 4. High impact grinding is an efficient method to modify the structure of starch.

6 5. Starch with different degrees of gelatinization and crystallinity can be obtained. 